\title{
GESTÃo de RECURSOS HÍDRICOS: PERSPECTIVAS DO CONSUMO PER CAPITA DE ÁGUa EM CUIABÁ
}

\author{
MANAGEMENT OF HYDRIC RESOURCES: PROJECTION OF PER CAPITA WATER \\ CONSUMPTION IN CUIABA
}

\section{Welitom TTatom Pereira Da Silva}

Engenheiro Sanitarista. Mestrando em Ciências Florestais e Ambientais - FENF/UFMT.

Engenheiro Sanitarista em Indústria de Alimentos

\author{
LUCIANE MARIA DA SILVA \\ Economista. Mestranda em Ciências Florestais e Ambientais - FENF/UFMT. Economista da Secretaria de \\ Estado de Saúde de Mato Grosso
}

\section{JoSÉ FRANKLIM CHICHORRO}

Engenheiro Florestal. Mestre e Doutor em Ciências Florestais - DEF/UFV. Professor-Adjunto da Universidade Federal do Espírito Santo. Professor convidado do Curso de Pós-Graduação em Ciências Florestais e Ambientais FENF/UFMT

Recebido: 26/02/07 Aceito: 16/10/07

\section{RESUMO}

Nesse trabalho buscou-se identificar o grau de participação das variáveis sócio-econômicas e climáticas na determinação do consumo per capita de água e propor um modelo estatístico capaz de projetar a demanda por água na região de Cuiabá. Os resultados indicaram a não interveniência das variáveis climáticas no fenômeno. Contribuíram à definição do consumo as variáveis classe sócio-econômica e o consumo per capita de energia elétrica. $\mathrm{O}$ modelo proposto para projeção do consumo apresentou $R^{2}$ de 0,7947 ; os resíduos não apresentaram distribuição normal, o que sugere ajustes. Essa ferramenta, associada à percepção das potencialidades e das limitações por gestores de recursos hídricos e formuladores de políticas públicas, pode ser utilizada na regulação do consumo per capita, e, desse modo, alcançar a otimização dos recursos disponíveis e, ainda, contribuir para a perspectiva sustentável dos recursos hídricos.

PALAVRAS-CHAVE: Água, planejamento, modelagem, regulação.

\section{INTRODUÇÃO}

Grandes são os desafios existentes na gestão dos serviços, produção e consumo dos recursos naturais na atualidade. Nesse sentido, no que se refere ao padrão de produção e consumo dos recursos hídricos, os gestores precisam buscar indicadores sustentáveis para transpor os riscos de escassez e de degradação ambiental no decorrer dos tempos. Na gestão, a demanda dos recursos hídricos atua como um componente importante a ser incorporado no planejamento, desenvolvimento e utilização dos recursos naturais para a racionalização do uso dos recursos finitos e dotados de valor econômico. Segundo Freitas e Santos (1999), dados da Organização Meteorológica Mundial mostram que o consumo mundial de água aumentou mais de seis vezes em menos de um século, mais do que o dobro das taxas de crescimento da população, e continua a crescer com a elevação do consumo nos setores agrícola, industrial e doméstico. Esses estudos demonstraram também que, nos próximos anos, a situação global das reservas hídricas tenderá a crises tanto no aspecto quantitativo quanto no qualitativo, caso não haja ações que visem à flexibilização da gestão dos recursos hídricos nos seus diferentes potenciais de usos.

No caso dos recursos ambientais, considerada a estrutura de crescimento das cidades, os gestores precisam adotar modelos de planejamento que observem os componentes: uso múltiplo e sustentabilidade dos bens e serviços ambientais. Nisso está a relevân-cia de se encontrar um fator analítico das informaçôes disponíveis sobre a per capita consumida dos recursos hídricos como ferramenta de gestão. 
A previsão de demandas reais de recursos hídricos, com base em valores tabelados ou dados de municípios semelhantes na elaboração de projetos de abastecimentos de água, pode ser questionável quando padronizada, pois há co-variação do consumo numa comunidade, conforme fatores, tais como, nível sócio-econômico, industrialização, clima, porte, características e topografia, percentual de medição do consumo de água, custo da tarifa, entre outros, destacam Fernandes Neto et al (2004).

Para fins de análise dos elementos intervenientes no consumo per capita de água, foram consideradas enquanto variáveis - o nível sócio-econômico da população e as variantes econômica e climática. Alguns estudos apontaram outras vertentes analíticas, a exemplo de Amaral e Shirota (2002), que estudaram os efeitos dos componentes sazonais e o ciclo de tendência do consumo de água para estimativa de uma média para a cidade de Piracicaba-SP. Os resultados mostraram que o consumo da água estava estreitamente ligado a um forte componente sazonal e diretamente proporcional à temperatura.

Também Zhou et al (apud Fernandes Neto et al, 2004, p. 102) avaliaram os efeitos da temperatura na cota per capita de água na cidade australiana de Melbourne. Detectaram uma relação complexa entre essas duas variáveis, com duas regressōes representando o fenômeno. A primeira equação de regressão foi obtida à temperatura inferior a $39^{\circ} \mathrm{C}$ e a segunda para temperaturas superiores a este valor.

Campos e Sperling (apud Fernandes Neto, 2004, p. 102), num outro estudo, relacionaram classe econômica (alta, média alta, média, média baixa e baixa) e o consumo per capita de água, levantamento este realizado em nove bairros de Belo Horizonte e Contagem-MG. Os resultados apresentaram correções bastante significativas $\left(\mathrm{R}^{2}=0,942\right)$.

O estudo per capita deste trabalho aplica-se à cidade de Cuiabá, localizada na região centro-sul do estado de Mato Grosso, e considerada hoje um dos pólos de desenvolvimento da região Centro-oeste do Brasil. Este trabalho buscou identificar o grau de participação das variáveis sócio-econômicas e climáticas na determinação do consumo per capita de água, a fim de apresentar uma proposta de modelo estatístico capaz de projetar a demanda de água na regiāo de Cuiabá. A escolha pelo uso das variáveis climáticas e sócio-econômicas podem auxiliar gestores e formuladores de políticas públicas no planejamento e regulação do consumo de água, tendo em vista as potencialidades e limitações dos recursos disponíveis.

\section{MÉTODOS}

$\mathrm{Na}$ presente investigação, adotou-se como universo populacional em análise todos os bairros de Cuiabá. Optou-se, ainda, pela estratificação conforme as categorias de classificação da população, utilizadas pelo IBGE (baixa, médio-baixo, média, médio-alta e alta) e pela definição de um bairro e sua respectiva classe sócio-econômica como uma unidade amostral. A renda média aritmética das classes sócio-econômicas está disposta na Tabela 1 , conforme apresentado no Perfil Socioeconômico de Cuiabá (Cuiabá, 2004).

A partir desses pressupostos, considerou-se, para fins de realização

Tabela I - Renda média aritmética por classe sócio-econômica

\begin{tabular}{cc}
\hline Classe sócio-econômica & $\begin{array}{c}\text { Rendimento nominal mediano mensal dos } \\
\text { responsáveis por domicílio }\end{array}$ \\
\hline Renda média de Cuiabá & 7,49 S.M. \\
Renda baixa & Abaixo de 2,91 S.M. \\
Renda média-baixa & De 2,91 S.M. a 5,65 S.M. \\
Renda média & De 5,66 S.M. a 11,65 S.M. \\
Renda Médio-Alta & De 11,66 S.M. a 21,94 S.M. \\
Renda alta & Acima de 21,94 S.M. \\
\hline
\end{tabular}

S.M.: salário mínimo

Fonte: IPDU - Cuiabá (2004)

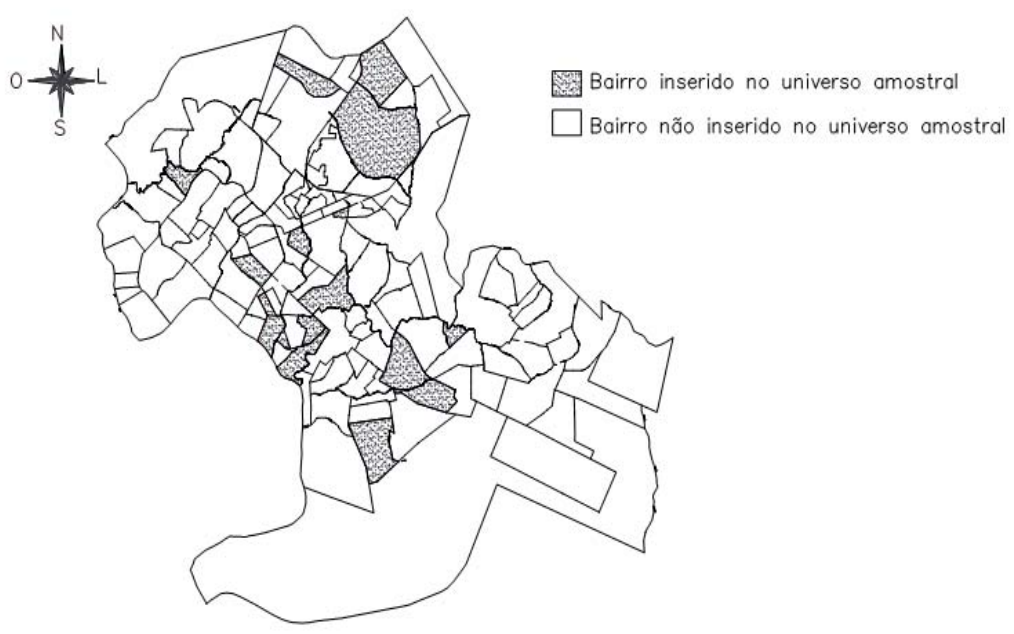

Figura I - Mapa de Cuiabá e bairros pertencentes no universo amostral do estudo, o método de amostragem aleatória estratificada. $\mathrm{O}$ número de unidades amostrais (n) foi definido em $10 \%$ de cada extrato. A Figura 1 apresenta o mapa do município de Cuiabá e as unidades amostrais selecionadas.

Quanto às variáveis de interesse e intervenientes no consumo per capita de água, adotaram-se algumas variáveis definidas pela CETESB (1978), a saber: a população por bairro, a temperatura média mensal, a umidade relativa do ar média mensal, o índice pluviométrico, a sazonalidade e a renda per capita. Os dados foram coletados considerando uma série histórica de 6 anos, cujo período abrangeu janeiro de 2000 à setembro de 2006. Essas variáveis foram levantadas junto a quatro fontes principais: Sanecap (Agência de Saneamento da Capital), Grupo Rede-Cemat (Centrais Elétricas Mato-grossenses), Cuiabá (Instituto de Pesquisa e Desenvolvimento Urbano de Cuiabá) e INMET (Instituto Nacional de Meteorologia). Foram utilizados os softwares SPSS (Statistical Package for the Social 
Sciences) e TableCurve para realização das análises estatísticas. As variáveis intervenientes foram inseridas como independentes e o consumo per capita de água como variável dependente. Para o tratamento dos dados utilizou-se a estatística descritiva, análise de correlação, a elaboração de gráficos de dispersão, o agrupamento hierárquico de cluster e, por fim, a modelagem estatística e validação do modelo com base em análise residual. Tais procedimentos tiveram a finalidade de avaliar possíveis interveniências sobre o consumo per capita de água.

Em relação ao modelo estatístico, a existência de um número razoável de variáveis intervenientes orientou a utilização da análise de regressão múltipla e a correlação como indicador limitante da participação dessas variáveis no modelo. Portanto, foram consideradas no modelo as variáveis explicativas, aquelas que apresentaram maiores coeficientes de correlação. A partir das variáveis reduzidas, o software TableCurve localizou os possíveis modelos, apresentou os parâmetros estatísticos e os resíduos. O modelo de regressão linear múltipla pode ser exemplificado conforme a Equação 1, a seguir:

$\mathrm{Y}=\beta_{\mathrm{o}}+\beta_{1} \cdot \mathrm{X}_{1}+$

$+\beta_{2} \cdot X_{2}+\ldots+\beta_{k} \cdot X_{k}+\varepsilon$

Onde:

$Y=$ Variável dependente; $\beta_{0}, \beta_{1}, \beta_{2}, \ldots \beta_{k}=$ Coeficientes; $\mathrm{X}_{1}, \mathrm{X}_{2}, \ldots \mathrm{X}_{\mathrm{k}}=$ Variáveis independentes e $\varepsilon=$ Erro.

\section{RESULTADOS E DISCUSSÃO}

Foram utilizadas 6480 observaçôes, cujas variáveis foram classificadas de acordo com a classe sócio-econômica (IPDU), mês, sazonalidade (Saz.), índice pluviométrico (IP), temperatura (Temp), umidade relativa (UR), consumo per capita de energia (CpercE) e tarifa do consumo de água $\left(\mathrm{R} \$ / \mathrm{m}^{3}\right)$. As informações constantes na Tabela 2 se referem às tarifas aplicadas ao consumidor, de acordo com o volume consumido por residência.

A validação estatística da amostra (n) foi efetivada pelo cálculo do tamanho da amostra aleatória estratificada para estimativas de médias para população finita, conforme proposto por Martins (2002). Os cálculos indicaram que $n$ de 385 observações seriam suficientes, entretanto, o realizado foi de 720 , superior ao $n$ ideal para a validação

Tabela 2 - Tabela tarifária do consumidor, categoria residencial

\begin{tabular}{cc}
\hline Intervalo da faixa & Alíquota preço $/ \mathrm{m}^{3}\left(\mathrm{R} \$ / \mathrm{m}^{3}\right)$ \\
\hline de 0 a 10 & 1,12 \\
de 11 a 20 & 1,68 \\
de 21 a 30 & 2,80 \\
de 31 a 40 & 3,70 \\
Acima de 40 & 5,56
\end{tabular}

Fonte: www.sanecap.com.br

estatística. Por essa razão, deduziu-se que a amostragem era estatisticamente representativa. Utilizou-se a estatística a fim de provar que a amostragem era representativa.

A estatística descritiva é apresentada na Tabela 3. Vale destacar que os valores médios do consumo per capita de água de 175 L/hab.dia são diferentes do da média nacional, em que o consumo atinge $150 \mathrm{~L} / \mathrm{hab}$.dia. Para as cinco classes sócio-econômicas, verificou-se menor desvio padrão para a tarifa de água e maior para o índice pluviométrico, pressupondo que o comportamento do valor da tarifa apresenta valores próximos entre si, embora o mesmo não possa ser deduzido em relação ao índice pluviométrico, assinalado pela forte presença da sazonalidade (Piaia, 1997).

A Tabela 4 apresenta a matriz dos coeficientes de correlação entre as variáveis analisadas. $\mathrm{O}$ coeficiente de correlação (r) é uma medida de associação linear, na prática se $r>0,70 \mathrm{ou}$ $r<-0,70$, e $n \geq 30$, diz-se que há uma forte correlação linear (Martins, 2002).

Observou-se forte correlação linear à variável classe sócio-econômica e correlaçóes fracas positiva e negativa, às variáveis - consumo per capita de energia e tarifa de água, respectivamente. A representação gráfica de variáveis quantitativas permitiu compreender o comportamento conjunto das variáveis quanto à existência ou não de associação entre elas. Um dispositivo bastante útil para se verificar esta associação é o gráfico de dispersão, segundo Bussab e Morettin (2006). A Figura 2 sugeriu uma associação entre as variáveis - consumo per capita de água e classe sócioeconômica, do tipo exponencial. Em outras palavras, o gráfico de dispersão (Figura 2) sugeriu que, à medida que ascendem as classes sócio-econômicas há um crescimento no consumo per capita de água, comportamento congruente com a literatura clássica.
Em referência às Figuras 3, 6 e 7, estas indicaram a ausência de interação entre as variáveis, sugerindo então a nulidade de associação entre a variáveis temperatura do ar, índice pluviométrico e umidade relativa com o consumo per capita de água. Tal resultado também se confirmou, de acordo com a Tabela 4, que foram observados baixíssimos coeficientes de correlação. Ao comparar esse resultado com a literatura clássica, constatou-se uma especificidade local: a nulidade de correlação entre variáveis climáticas e a demanda de água. Uma das possíveis justificativas se apóia na sazonalidade, com dois períodos bem definidos na região e com baixa variabilidade de temperatura (Piaia, 1997).

A análise gráfica das Figuras 4 e 5 apresentaram tendências de correlação, uma vez que mostram tendência quadrática decrescente e formação de nuvens de dispersão, respectivamente. Observou-se na Figura 4 que o incremento no valor da tarifa de água implicou redução da demanda pelo recurso, no entanto, o coeficiente de correlação apresentado na Tabela 4 (Correlação de Pearson $=-0,121)$ não confirmou esta observação, havendo, portanto, uma fraca associação entre as duas variáveis.

O gráfico de dispersão, exposto na Figura 5, apresentou nuvens de dispersão com diferentes tendências de comportamento entre as variáveis de consumo per capita de energia e consumo per capita de água, o que sugeriu a existência de agrupamentos de bairros com características específicas de consumo destes recursos. Assim, seria possível sugerir uma possível reclassificação dos bairros por faixas de consumo per capita de energia, o que auxiliaria na inferência sobre a demanda de outros recursos naturais.

Tendo em vista ainda a seleção das variáveis intervenientes na demanda de água, foi realizada a análise de agrupamento de Cluster que, segun- 
Tabela 3 - Análise estatística descritiva das variáveis envolvidas

\begin{tabular}{ccccccc}
\hline & $\mathrm{N}$ & Mínimo & Máximo & Média & Desvio padrão & Variância \\
\hline IBGE & 720 & 1 & 5 & 2,63 & 1,112 & 1,236 \\
Mês & 720 & 1 & 12 & 6,20 & 3,353 & 11,242 \\
Saz. & 720 & 1 & 2 & 1,49 & 0,500 & 0,250 \\
IP & 720 & 0,0 & 355,5 & 105,742 & 89,8549 & 8073,896 \\
Temp & 720 & 18,1 & 28,3 & 25,758 & 2,2213 & 4,934 \\
UR & 720 & 52 & 96 & 72,82 & 10,083 & 101,665 \\
CpercA & 720 & 76.780 & 365,129 & 174,86276 & 68,968683 & 4756,679 \\
CpercE & 720 & 0,237 & 18,418 & 3,35508 & 3,295932 & 10,863 \\
$\left(\mathrm{R} \$ / \mathrm{m}^{3}\right)$ & 720 & 1,12 & 3,70 & 1,7528 & 0,38330 & 0,147 \\
\hline
\end{tabular}

Tabela 4 - Coeficientes de correlação das variáveis analisadas

\begin{tabular}{|c|c|c|c|c|c|c|c|c|c|c|}
\hline & & IBGE & Mês & Saz. & IP & Temp & UR & CpercA & CpercE & $\mathrm{R} \$ / \mathrm{m}^{3}$ \\
\hline IBGE & $\begin{array}{l}\text { Correlação } \\
\text { de Pearson }\end{array}$ & 1 & 0,000 & 0,000 & 0,000 & 0,000 & 0,000 & $0,764^{* *}$ & $0,687^{* *}$ & $-0,213^{* *}$ \\
\hline Mês & $\begin{array}{l}\text { Correlação } \\
\text { de Pearson }\end{array}$ & 0,000 & 1 & $-0,364^{* *}$ & $-0,264^{* *}$ & $0,102^{* *}$ & $-0,468^{* *}$ & 0,43 & 0,014 & 0,005 \\
\hline Saz. & $\begin{array}{l}\text { Correlação } \\
\text { de Pearson }\end{array}$ & 0,000 & $-0,364^{* *}$ & 1 & $0,726^{* *}$ & $0,489^{* *}$ & $0,600^{* *}$ & $-0,020$ & 0,044 & $-0,029$ \\
\hline IP & $\begin{array}{l}\text { Correlação } \\
\text { de Pearson }\end{array}$ & 0,000 & $-0,264^{* *}$ & $0,726^{* *}$ & 1 & $0,543^{* *}$ & $0,617^{* *}$ & 0,001 & 0,046 & $-0,010$ \\
\hline Temp & $\begin{array}{l}\text { Correlação } \\
\text { de Pearson }\end{array}$ & 0,000 & $0,102^{* *}$ & $0,489^{* *}$ & $0,543^{* *}$ & 1 & $0,308^{* *}$ & 0,005 & 0,028 & $-0,016$ \\
\hline UR & $\begin{array}{l}\text { Correlação } \\
\text { de Pearson }\end{array}$ & 0,000 & $-0,468^{* *}$ & $00,600^{* *}$ & $0,617^{* *}$ & $0,308^{* *}$ & 1 & $-0,028$ & 0,028 & $-0,036$ \\
\hline CpercA & $\begin{array}{l}\text { Correlação } \\
\text { de Pearson }\end{array}$ & $0,764^{* *}$ & 0,043 & $-0,020$ & 0,001 & 0,005 & $-0,028$ & 1 & $0,544^{* *}$ & $-0,121^{* *}$ \\
\hline CpercE & $\begin{array}{l}\text { Correlação } \\
\text { de Pearson }\end{array}$ & $0,687^{* *}$ & 0,014 & 0,044 & 0,046 & 0,028 & 0,028 & $0,544^{* *}$ & 1 & 0,002 \\
\hline$\left(\mathrm{R} \$ / \mathrm{m}^{3}\right)$ & $\begin{array}{l}\text { Correlação } \\
\text { de Pearson }\end{array}$ & $-0,213^{* *}$ & 0,005 & $-0,029$ & $-0,010$ & $-0,016$ & $-0,036$ & $-0,121^{* *}$ & 0,002 & 1 \\
\hline
\end{tabular}

**Correlação significativa ao nível de 0,01 .

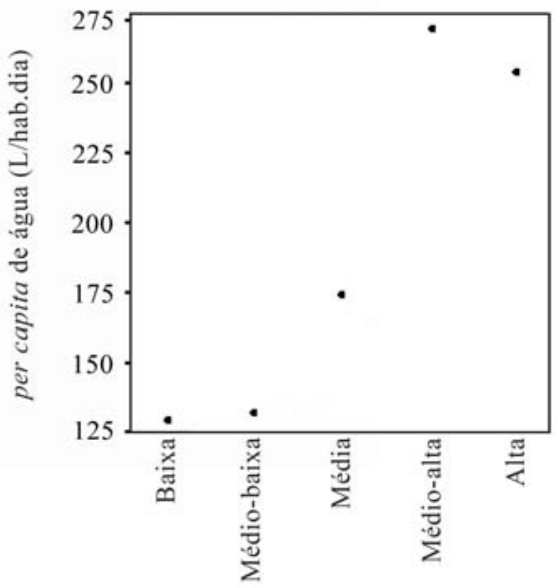

Classe sócio-econômica

Figura 2 - Gráfico de dispersão para as variáveis $X$ : classe sócioeconômica e Y: per capita de água

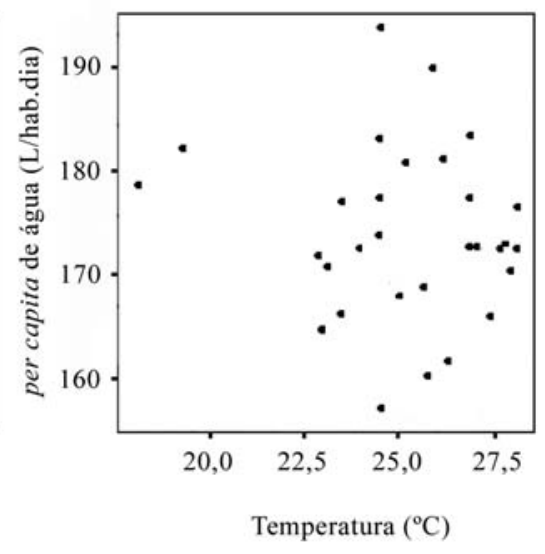

Figura 3 - Gráfico de dispersão para as variáveis $X$ : temperatura e Y: per capita de água 


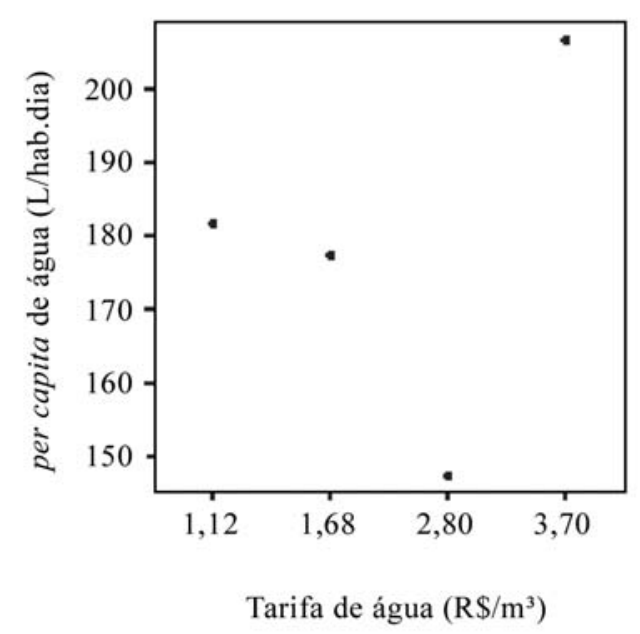

Figura 4 - Gráfico de dispersão para as variáveis $X:$ tarifa de água $\mathrm{e}$ Y: per capita de água

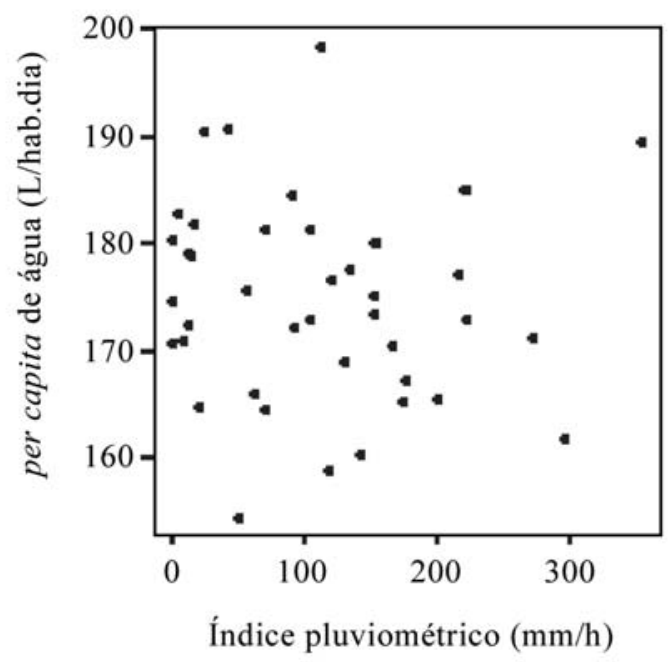

Figura 6 - Gráfico de dispersão para as variáveis $X$ : índice pluviométrico e Y: per capita de água

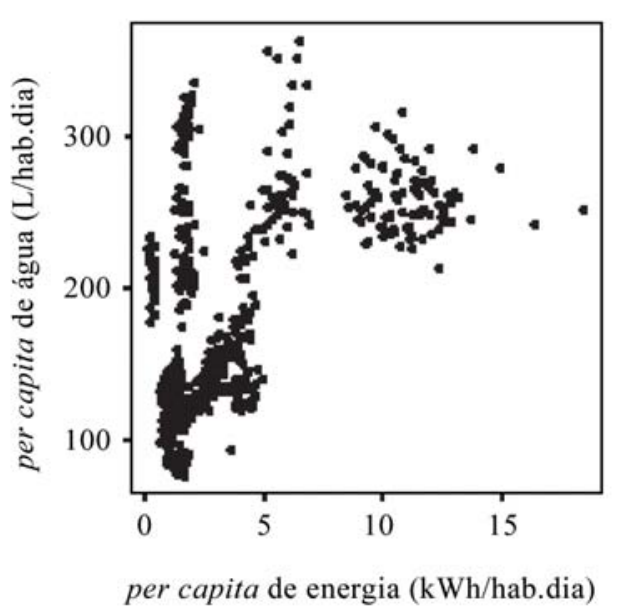

Figura 5 - Gráfico de dispersão para as variáveis $X$ : per capita de energia e Y: per capita de água

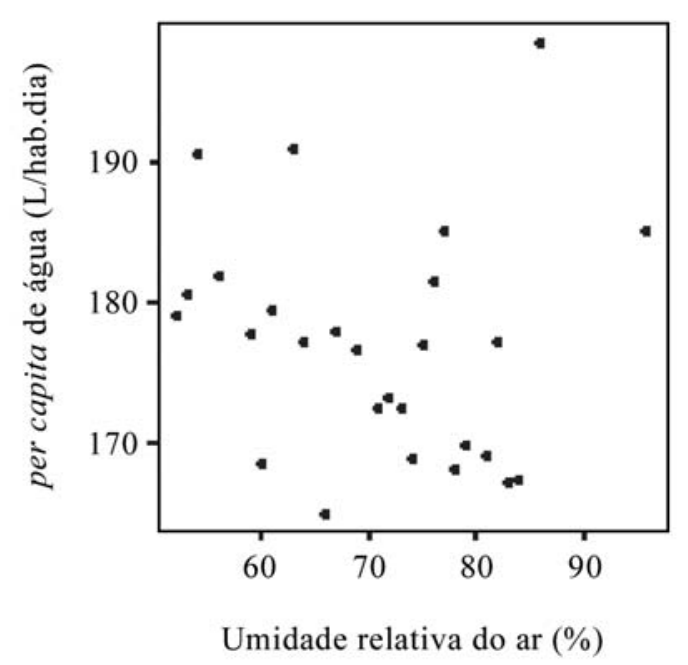

Figura 7 - Gráfico de dispersão para as variáveis $X$ : umidade relativa do ar e Y: per capita de água do Hair (1998), trata-se de um conjunto de técnicas estatísticas cujo objetivo é agrupar objetos segundo suas características, formando grupos ou conglomerados homogêneos. No dendograma exibido na Figura 8, as linhas verticais representam os conglomerados unidos; enquanto que as linhas horizontais, a distância euclidiana entre as variáveis. Daí poder-se inferir acerca do número de agrupamentos e quais as variáveis que se agrupam entre si. Neste caso, pode-se verificar a existência de 2 conglomerados. As variáveis constituintes do primeiro conglomerado foram: classe sócio-econômica, consumo per capita de água e energia, mês e tarifa de água; já as do segundo conglomerado as variáveis climáticas.
Em relação à Figura 8, vale destacar que essas associaçōes foram obtidas também na análise de correlação e nos gráficos de dispersão. Trata-se do agrupamento das variáveis consumo per capita de água e classe sócio-econômica e do agrupamento destas com o consumo per capita de energia. Resultados estes também obtidos com a análise de correlação e gráficos de dispersão, a partir da qual é possível afirmar que as variáveis intervenientes foram a classe sócio-econômica e o consumo per capita de energia.

Da seleção das variáveis - classe sócio-econômica e consumo per capita de energia, como variáveis explicativas ao consumo per capita de água, buscou-se um modelo estatístico através de técnicas de regressão. Obteve-se, então, o modelo estatístico apresentado pela seguinte equação linear múltipla, Equação 2:

$\mathrm{Y}=\beta_{0}+\beta_{1} \cdot \mathrm{X}+\beta_{2} \cdot 1 \mathrm{ny}+\beta_{3} \cdot \mathrm{X}^{2}+$

$+\beta_{4} \cdot(1 \mathrm{ny})^{2}+\beta_{5} \cdot \mathrm{x} \cdot 1 \mathrm{ny}+$

$+\beta_{6} \cdot x^{3}+\beta_{7} \cdot(1 \mathrm{ny})^{3}+$

$+\beta_{8} \cdot \mathrm{x}(1 \mathrm{ny})^{2}+\beta_{9} \cdot \mathrm{x}^{2} \cdot 1 \mathrm{ny}$

Os coeficientes do modelo, em nível de significância ao nível de 1\% de probabilidade pelo Teste F, foram: $\beta_{0}=172,0400859 ; \beta_{1}=-120,74278$; $\beta_{2}=-49,1065925 ; \beta_{3}=59,94214711$; $\beta_{4}=72,51750503 ; \beta_{5}=-4,01210981$; $\beta_{6}=-5,20276914 ; \beta_{7}=7,949295456$; $\beta_{8}=-21,0824017 ; \beta_{9}=1,571376855$ 
sendo $\mathbf{x}=$ classe sócio-econômica; $\mathbf{y}=$ consumo per capita de energia; $\mathrm{Y}=$ consumo per capita de água. Tal modelo estatístico obteve-se $\mathrm{R}^{2}$ ajustado (coeficiente de determinação múltipla) de 0,7947168384 . A Figura 9 explicita o gráfico do modelo estatístico adotado e os valores observados.

A verificação da adequação do modelo foi realizada por meio de análise residual, constada nas Figuras 10 e 11 , gráfico $p \times p$ para normalidade de resíduos e histograma, respectivamente. $\mathrm{Na}$ Tabela 5, pelo teste de aderência à normalidade de Kolmogorov-Smirnov.

O gráfico $p \times p$ para normalidade de resíduos mostra a existência de agrupamentos e elementos discrepantes, resultantes, a priori, da existência de subgrupos dentro das classes sócioeconômicas, ou mesmo de erros de medidas, daí sugerir-se uma investigação das possíveis causas dos desvios. Ao analisar o histograma, concluiu-se, a princípio, que os resíduos apresentaram distribuição normal uma vez que as freqüências apresentaram-se próximas à curva de distribuição normal. Contudo, o teste de KolmogorovSmirnov, indicado na Tabela 5, não confirmou a hipótese da normalidade. Ou seja, o modelo ajustado foi pouco competente à projeção do consumo per capita para a região de Cuiabá. Analisados os resíduos e diagnosticada uma violação das suposições iniciais, recomenda-se a verificação dos possíveis vieses para que o modelo possa se adequar aos dados e às suposiçôes feitas.

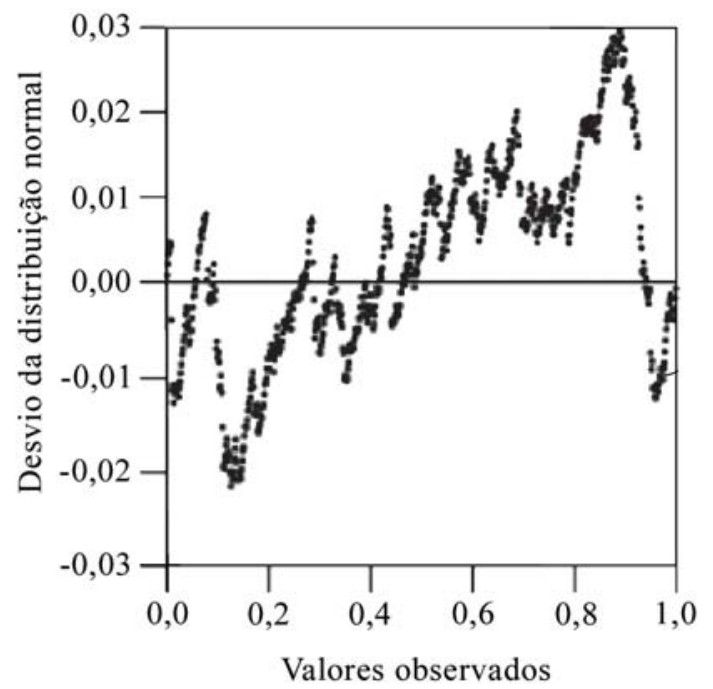

Figura 10 - Gráfico p x p para normalidade de resíduos

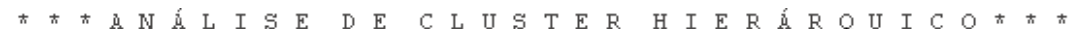

Dendograma segundo o método de Ward

Distância Euclidiana entre os conglomerados

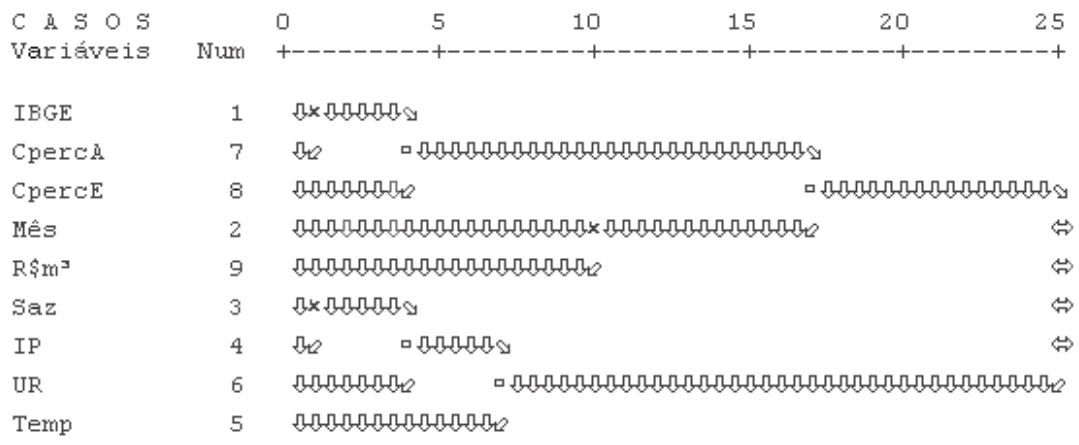

Figura 8 - Dendograma obtido da análise de agrupamento hierárquico utilizando nove variáveis: classe sócio-econômica (IPDU), consumo per capita de água (CpercA), consumo per capita de energia (CpercE), mês, tarifa de água $\left(R \$ / \mathrm{m}^{3}\right)$, sazonalidade (Saz), índice pluviométrico (IP), umidade relativa (UR) e temperatura do ar (Temp)

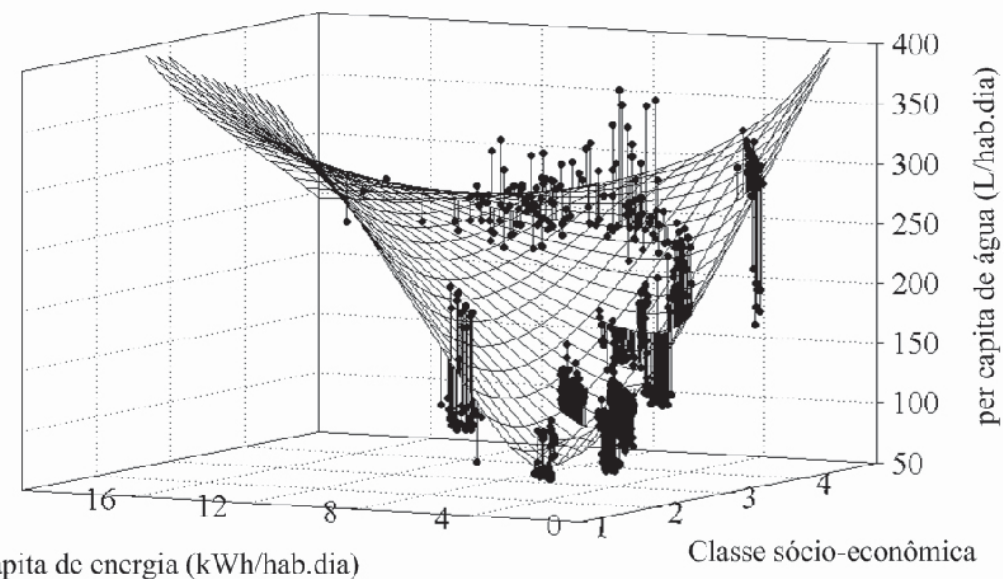

per capita de cncrgia (kWh/hab.dia)

Figura 9 - Gráfico tridimensional do modelo estatístico estimado e valores observados

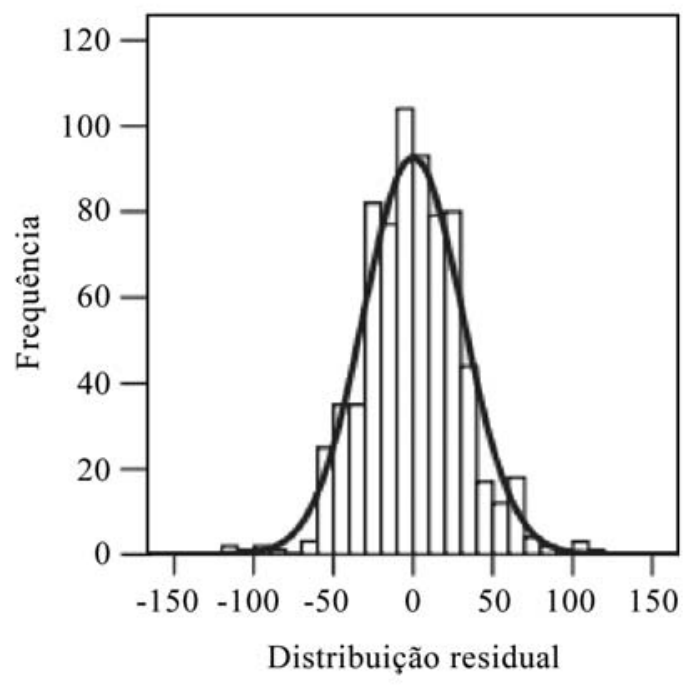

Figura I I - Histograma dos resíduos 
Tabela 5 - Teste de Kolmogorov-Smirnov aplicado aos resíduos

\begin{tabular}{|c|c|c|c|}
\hline \multicolumn{4}{|c|}{ Teste Kolmogorov-Smirnov para uma amostra } \\
\hline & & & Resíduos \\
\hline $\mathrm{N}$ & & & 720 \\
\hline \multirow[t]{2}{*}{ Parâmetro normal ${ }^{a}$} & Média & & 0,00 \\
\hline & Desvio padrão & & 32,029 \\
\hline \multirow[t]{3}{*}{ Diferenças extremas } & Absoluto & & 0,30 \\
\hline & Positivo & & 0,30 \\
\hline & Negativo & & $-0,025$ \\
\hline Z Kolmogorov-Smirnov & & & 0,0814 \\
\hline Sig. Asintót (bilateral) & & & 0,522 \\
\hline Sig. Monte Carlo & Sig. & & 0,508 \\
\hline \multirow[t]{2}{*}{ (bilateral) } & $99 \%$ Intervalo & Limite inferior & 0,495 \\
\hline & de confiança & Limite superior & 0,521 \\
\hline
\end{tabular}

a. Teste de distribuição normal.

\section{CONCLUSÕES}

Observou-se um valor médio de consumo per capita de água em Cuiabá de $175 \mathrm{~L} / \mathrm{hab}$.dia, valor este em consonância com os valores típicos para o porte da comunidade, conforme apresentado por von Sperling (1996).

Como ponto positivo, pode-se destacar a inferência sobre uma especificidade regional, a não interveniência dos fatores climáticos no consumo per capita de água, divergindo da literatura clássica. Uma das possíveis justificativas se apóia na sazonalidade local, com dois períodos bem definidos na região e com baixa variabilidade de temperatura (Piaia, 1997). Também, pode-se confirmar a premissa da correlação entre consumo de água e fatores sócio-econômicos, hipótese de diferenças significativas na distribuição do consumo per capita de água em função das diferentes condiçōes sócio-econômicas da população.

Como pontos negativos, no que se refere aos resultados da pesquisa, podese observar que o modelo estatístico proposto, embora com o valor de $\mathrm{R}^{2}$ ajustado de 0,7947 , não permitiu sua validação uma vez que seus resíduos não aderiram à distribuição normal, hipótese a ser aceita quando da validação de modelos (Gujarati, 2000). Por essa razão, recomenda-se que sejam realizados novos estudos voltados a adequações ao modelo proposto por meio de inserção e interação de variáveis econômicas.

$\mathrm{O}$ uso da modelagem para atendimento à gestão dos recursos hídricos traz a perspectiva de uma ferramenta útil que pode auxiliar na expansão e regulação do fornecimento da água, assumindo o contexto local como parâmetro de projeção e otimização nas variabilidades da demanda.

\section{REFERÊNCIAS}

AMARAL, A.M.P.; SHIROTA, R. Consumo residencial médio de água tratada: uma aplicação de modelos de séries temporais em Piracicaba. Revista Agrícola, v. 49, n. 1, p. 55-72, 2000.

BUSSAB, W.O.; MORETTIN, P.A. Estatística básica. 5. ed. São Paulo: Saraiva, 2006.

CAMPOS, H. M.; SPERLING, M. (1997) apud FERNADES NETO, M. L. et al. Avaliação da relevância dos parâmetros intervenientes no consumo per capita de água para os municípios de Minas Gerais. ABES, v. 9, n. 2, p. 100-107, 2004.

CETESB - COMPANHIA DE TECNOLOGIA DE SANEAMENTO AMBIENTAL. Técnica de abastecimento e tratamento de água. São Paulo: CETESB, 1978.

CUIABÁ. PREFEITURA MUNICIPAL. INSTITUTO DE PESQUISA E DESENVOLVIMENTO URBANO - IPDU. Perfil Socioeconômico de Cuiabá - Vol. II -Cuiabá: IPDU/AS\&M/Central de Texto, 405 p. 2004.

FERNADES NETO, M.L et al. Avaliação da relevância dos parâmetros intervenientes no consumo per capita de água para os municípios de Minas Gerais. ABES, v. 9, n. 2, p. 100-107, 2004.

FERREIRA, J. C. Mato Grosso e seus municípios. Cuiabá: SEDUC, 2001.

FREITAS, M. A. V.; SANTOS, A. H. M. Importância da Água e da Informação Hidrológica. In: O Estado das Águas no Brasil, 1 ed. Brasília. Ed. ANEEL/MME/ MMA-SRH/OMM, p. 13-16, 1999.

GUJARATI, D. N. Econometria básica. 3 ed. São Paulo: Pearson Makron Books, 864 p.2000.
HAIR, J. et al. Multivariate Data Analysis. Editora Prentice Hall, New Jersey, 1998.

INSTITUTO NACIONAL DE METEROLOGICO - INMET. Relatório climatológico. Várzea Grande: INMET, 4 p. (Relatório técnico, Rt-2001-2006). 2006.

MARTINS, G.A. Estatística geral e aplicada. 2. ed. São Paulo: Atlas, 2002.

PIAIA, Ivani Inêz. Geografia do Mato Grosso. $3^{\circ}$ Ed. EDUNIC, 1997.

SANECAP. AGÊNCIA DE SANEAMENTO DA CPITAL. Cálculo da conta. Disponível em: https://sanecap.locaweb.com.br/informacoes. php?IDCategoria=347 Acesso em: 08 nov. 2006.

SILVA, I. Re: Informaçóes de bairros - relatório Sanecap. Mensagem recebida por: <ttatom@universiabrasil.net> em: 17 de nov. 2006.

SOUZA, W.H.S. Dados da Pesquisa - relatório REDE CEMAT. Mensagem recebida por $<$ ttatom@universiabrasil.net $>$ em: 17 de nov. 2006

VON SPERLING, M. 2002 Princípio de tratamento biológico de águas Residuárias. Volume 3, lagoa de estabilização. 2a ed. Departamento de Eng. Sanitária e Ambiental - UFMG. 196p. 2002.

ZHOU, S. L. et al. Avaliação da relevância dos parâmetros intervenientes no consumo per capita de água para os municipios de Minas. 2001.

Endereço para correspondência:

Welitom Ttatom Pereira da Silva

Rua Novo Mato Grosso, $n^{\circ} 75$

Jardim Vista Alegre - Coxipó

78085-740 Cuiabá - MT - Brasil

Tel.: (65) 366 I-I 724

Celular: (65) 9284-0552

E-mail: ttatom@universiabrasil.net 